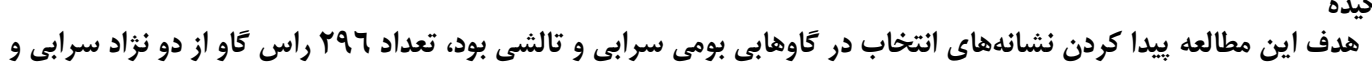

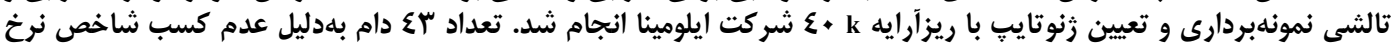

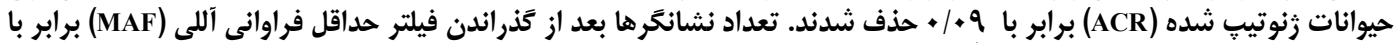

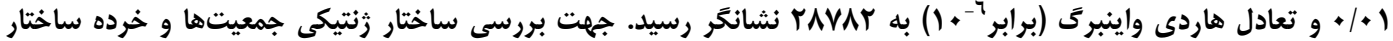

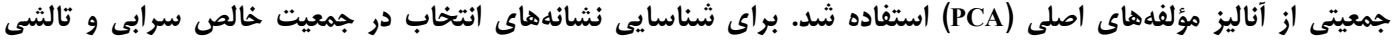

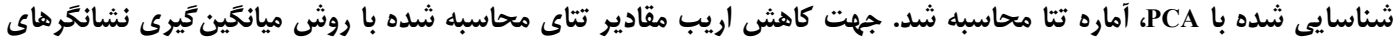

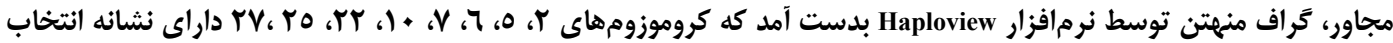

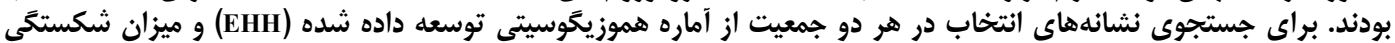

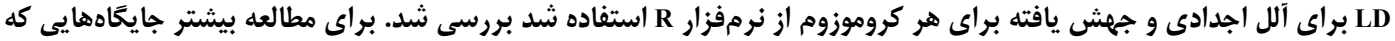

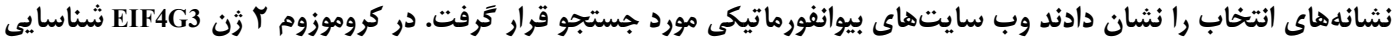

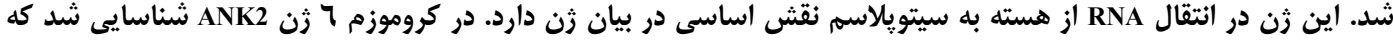

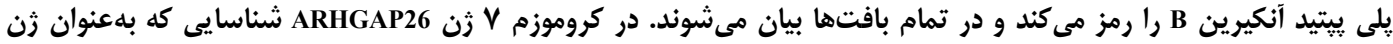

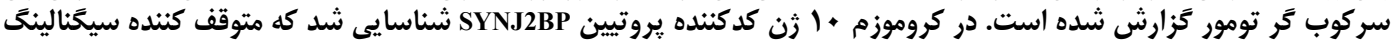

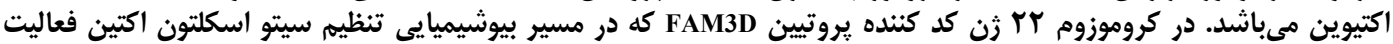

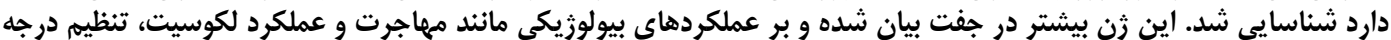

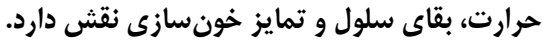

وازَهایى كليدى: آناليز مولفه هاى اصلى، آماره تتا، آماره هموزيگَوسيتى هايلوتايٍ توسعه يافته

بلهدليل وقوع نوتركيبى در اطـراف ايـن جايخـاه، عـدم تعـادل

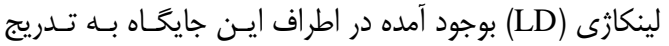

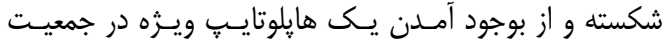

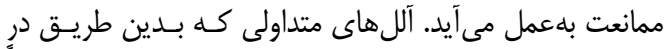

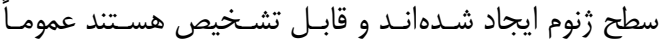

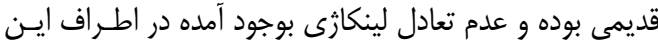

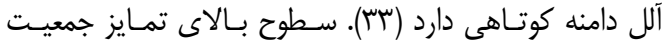

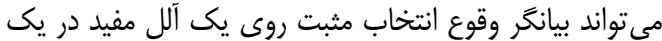

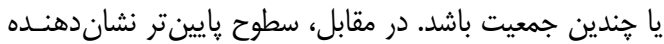

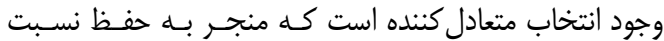

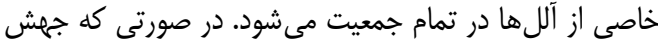

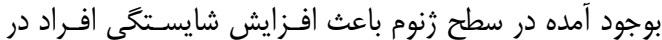

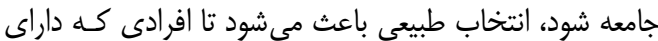

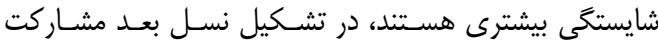

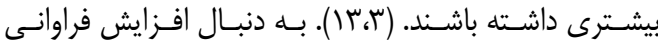

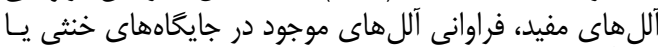

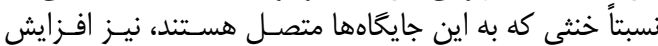

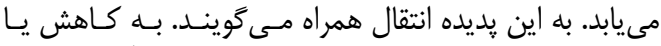

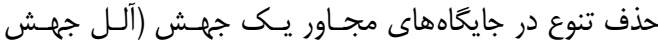

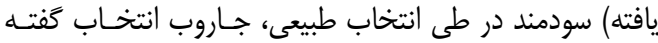

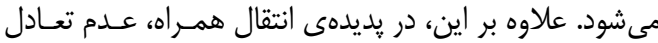

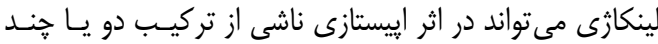

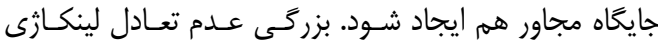

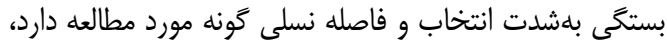

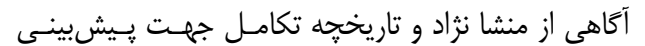

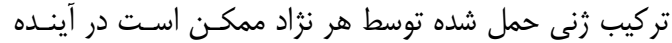
براى توصيف صفات مختلف مثل مقاومت به به بيمارى، استرس نوس

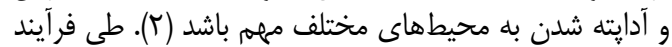

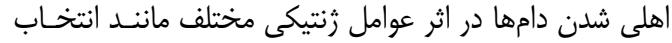

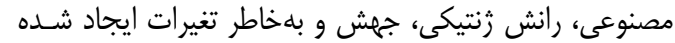

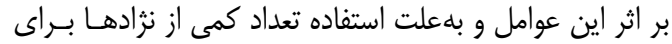

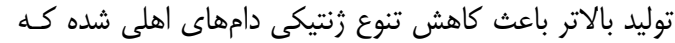

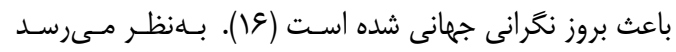

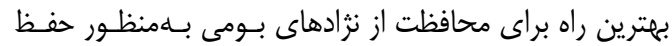

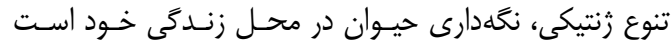

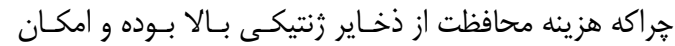

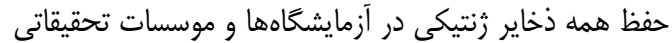

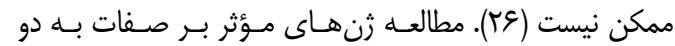

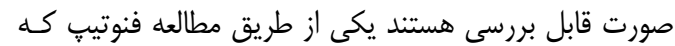

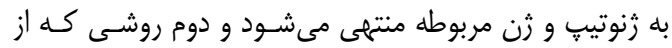

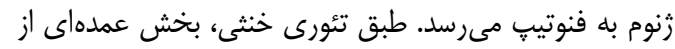

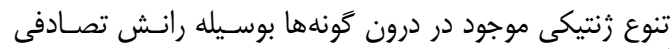

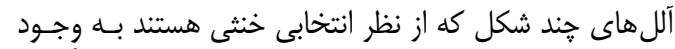

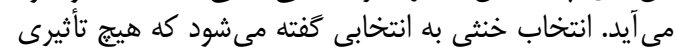

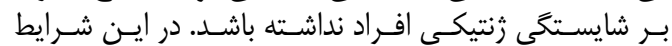

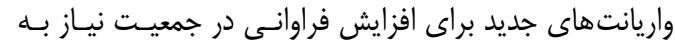

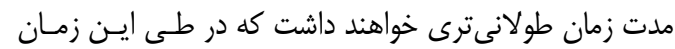




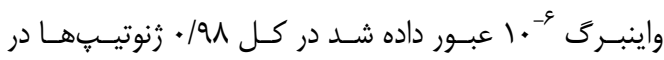

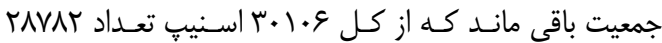

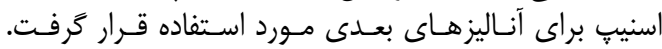

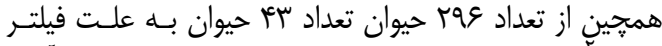
ACR

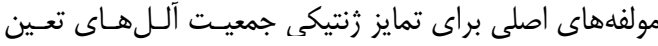

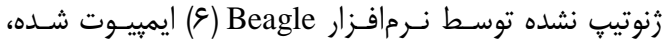

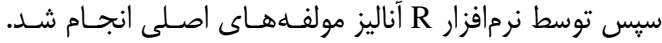

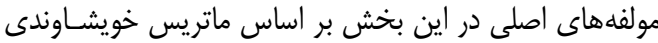

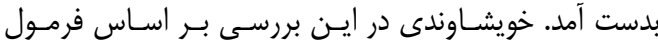

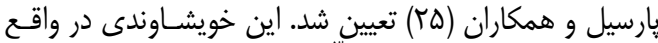

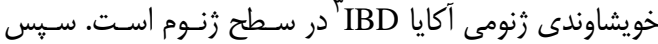

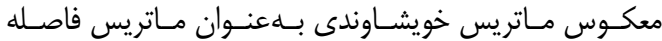

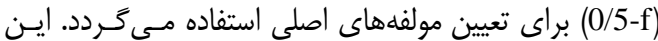

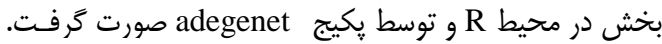

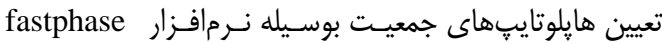

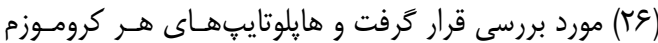

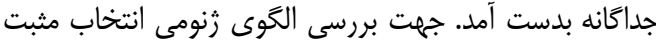

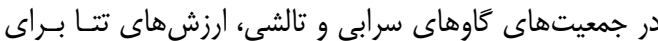

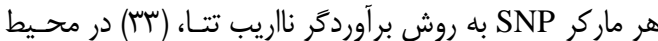

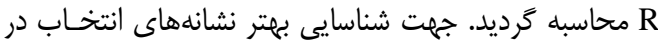

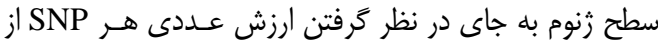

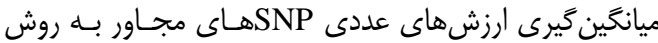

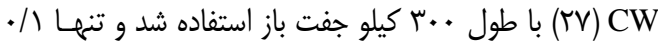

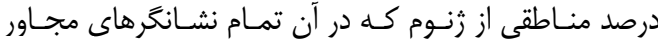

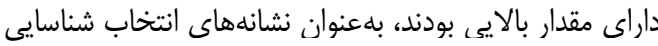

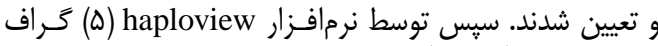

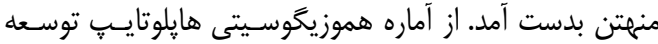

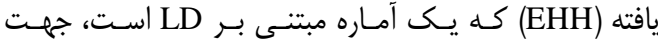

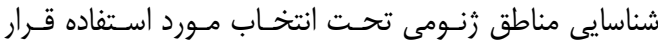

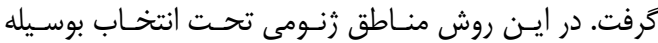

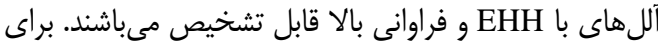

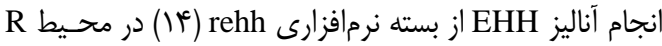

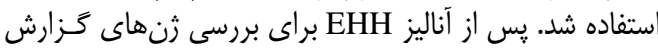

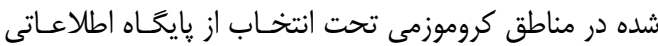
جنهـ Biomat Ensemble اطلاعاتى KeGG و david براى بررسى مسير بيوشـيميايى و آنتالوزى ثن هاى گزارش شده استفاده گرديد.

\section{نتايج و بحث تمايز زنتيكى جمعيت وريت}

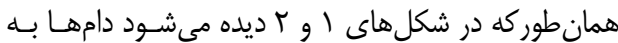

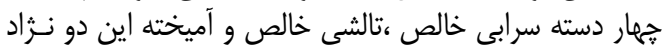

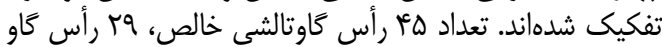

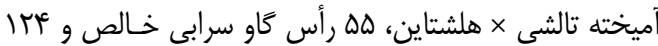

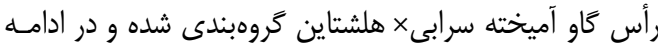

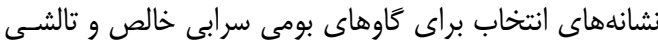
خالص مورد بررسى قرارگَرفت.

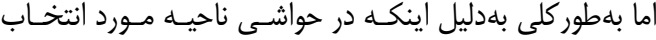

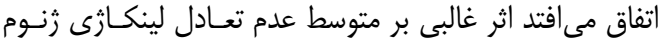

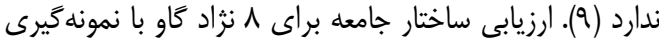

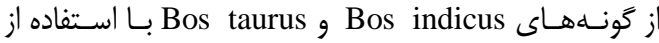

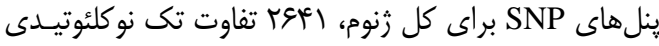

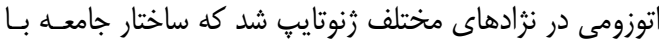

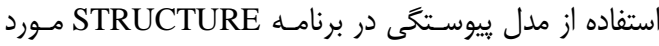

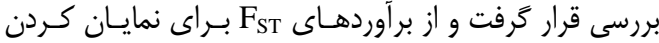

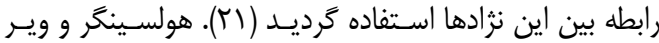

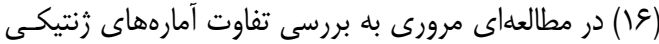

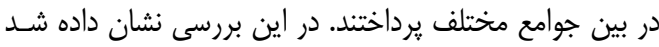

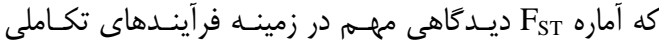

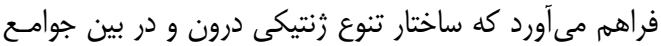

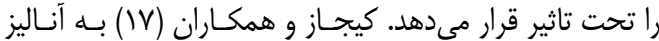

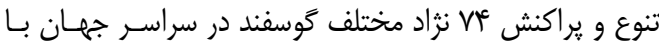

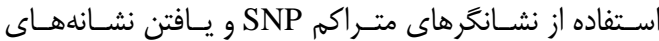

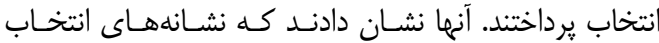

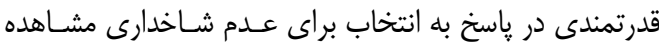

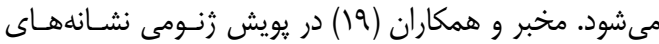

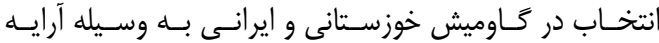

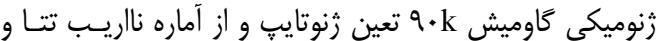

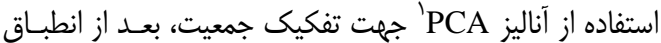

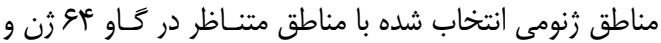

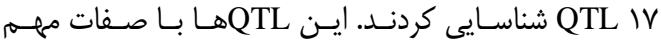

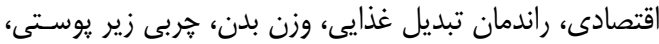

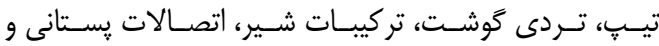

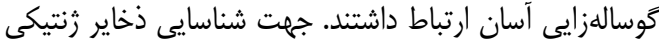

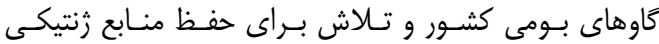

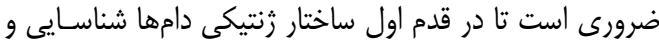

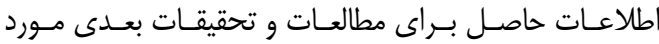

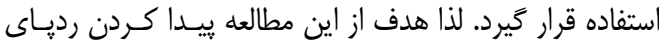

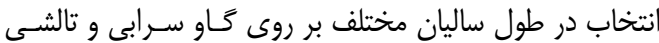

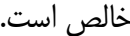

\section{مواد و روشها

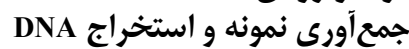

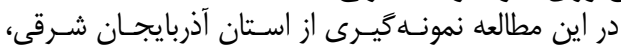

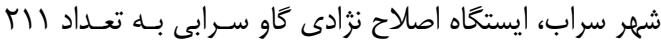

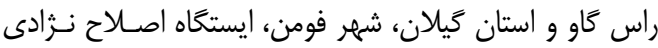

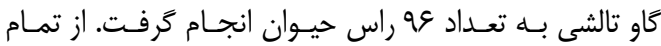

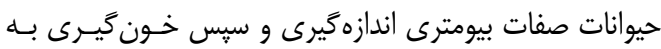

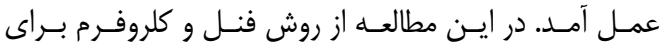

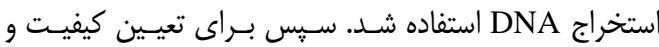

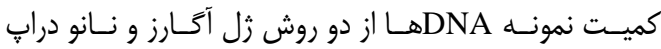

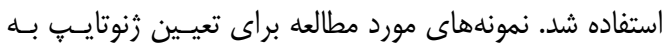

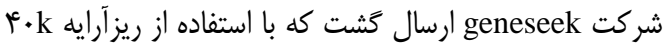

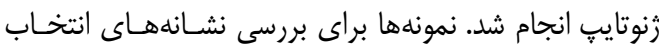

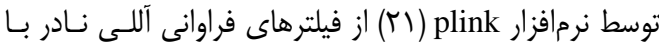

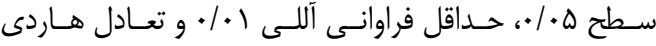


9. كاوش ثنومى نشانههاى انتخاب در كاوهاى بومى نزاد سرابى و تالشى ايران

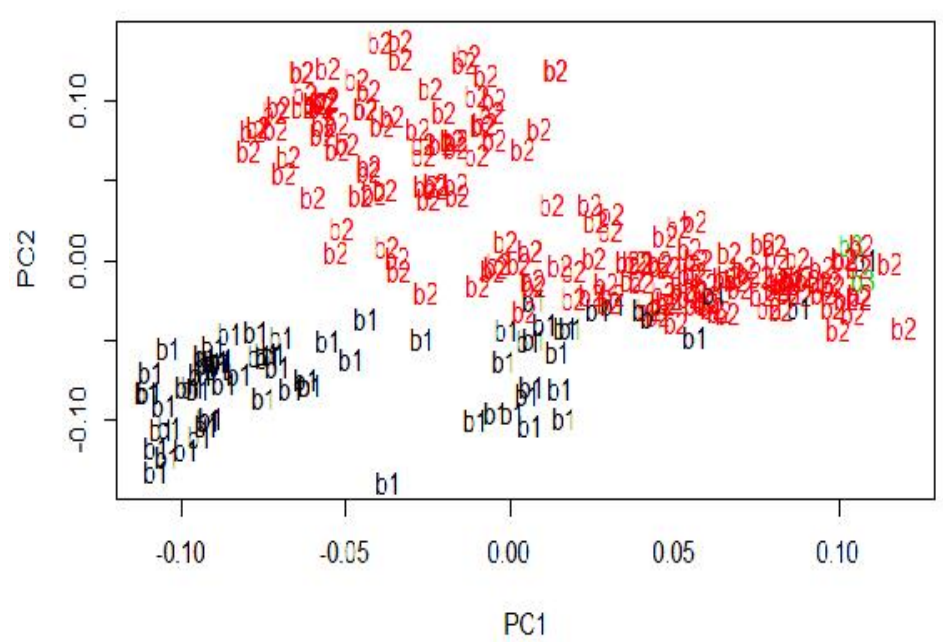

شكل ا- آناليز مولفههاى اصلى براى نزاد سرابى و تالشى جهت تفكيك نزادها در نرمافزار

Figure 1. Principal Component Analysis for Sarabi and Taleshi breed to classification breeds on R software

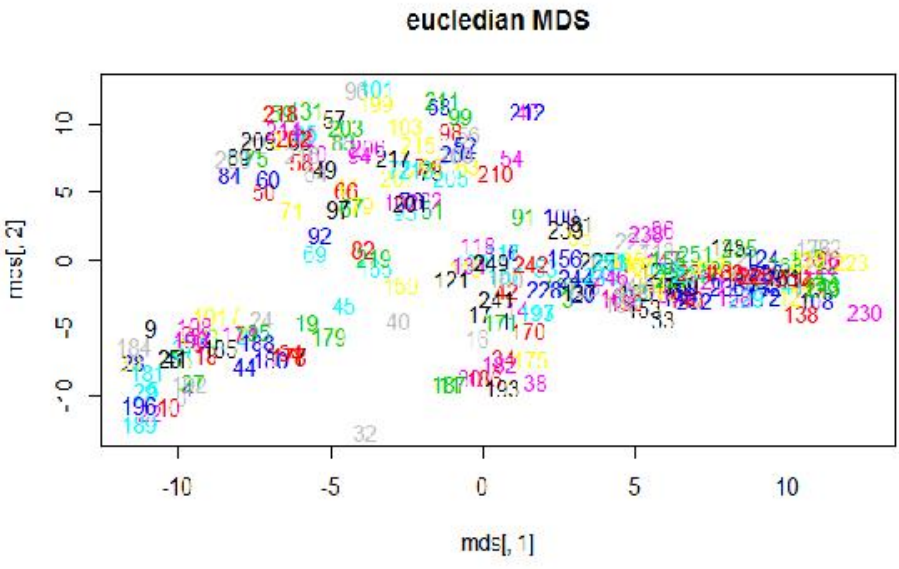

شكل r- آناليز مولفههاى اصلى براى نزاد سرابى و تالشى توسط نرمافزار R جهت مشخص نمودن شماره دام

Figure 2. Principal Component Analysis for Sarabi and Taleshi on R software to specify animal number

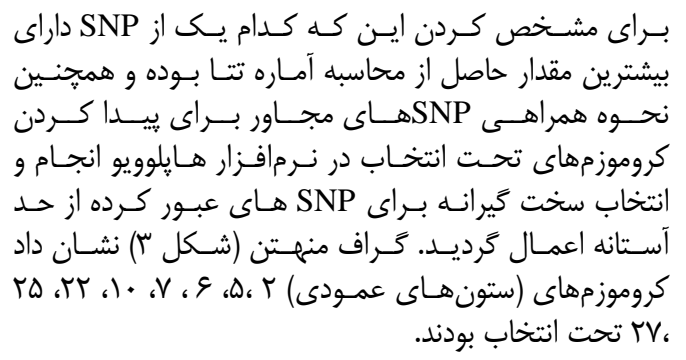

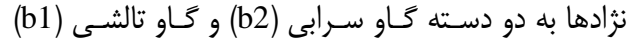

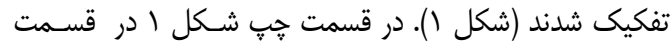

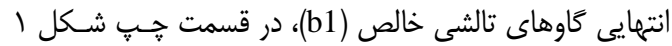

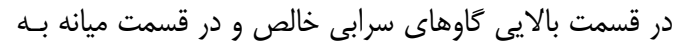

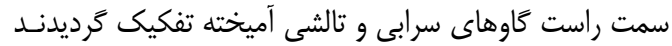

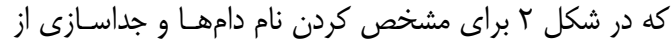

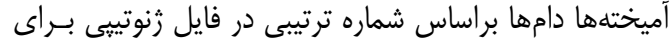

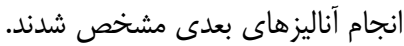

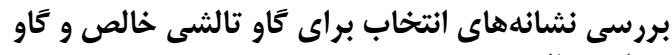
سرابى خالص نسانه 


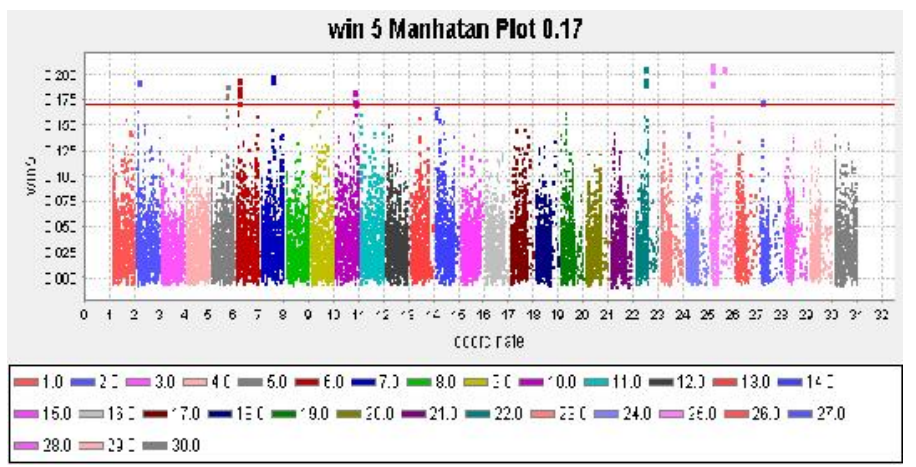

شكل س- كراف منهتن براى نشانهاى انتخاب كاو سرابى و تالشى خالص

Figure 3. Manhattan graph for signature selection in pure Sarabi and Taleshi

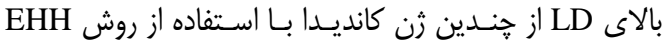

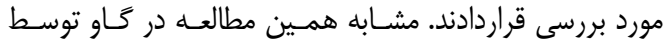

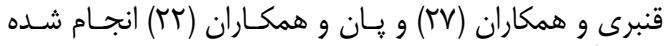

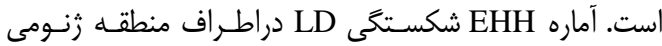

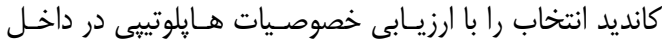
يك جمعيت مورد بررسى قرار مى بـدهد.

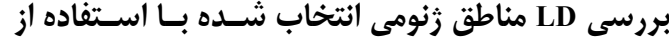

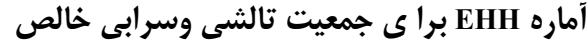

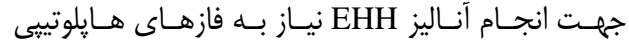

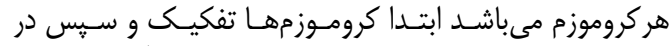

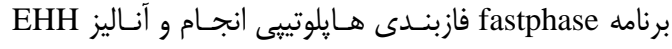

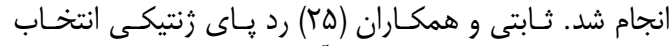

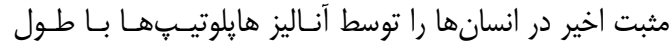
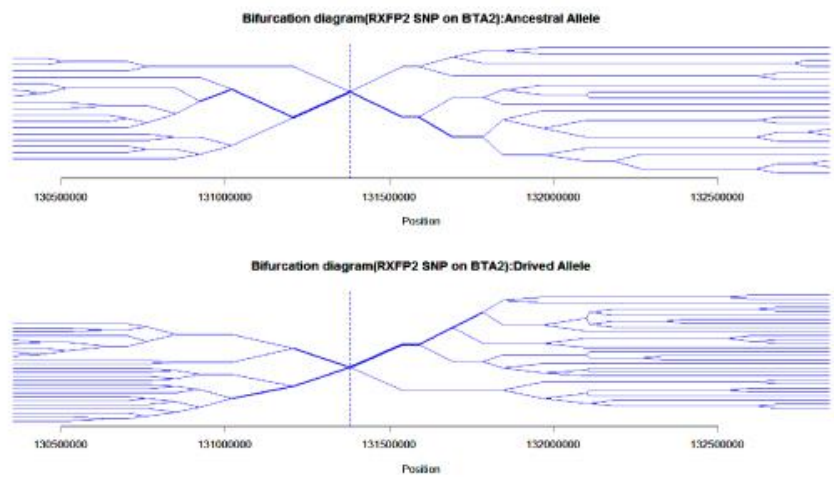

شكل ع- شكستخى LD براى آلل اجدادى و جهش يافته در كروموزم ب براى كاو تالشى

Figure 4. LD degradation for ancestral and derived allele at chromosome 2 for Taleshi cow
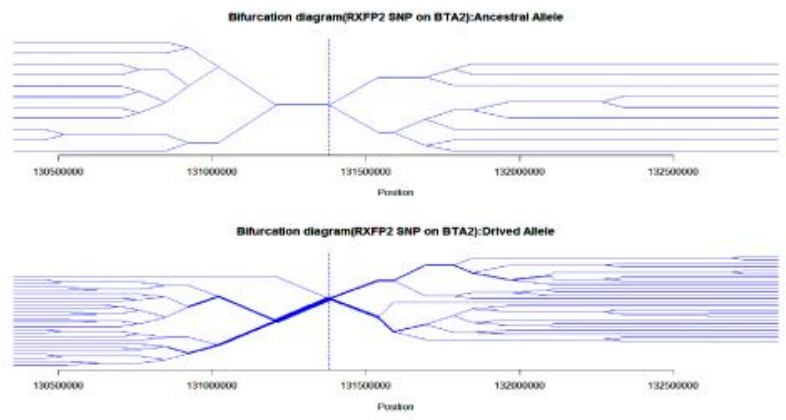

شكل ه- شكستكى LD براى آلل اجدادى و جهش يافته دركروموزم ז براى كاو سرابى

Figure 5. LD degradation for ancestral and derived allele at chromosome 2 for Sarabi cow 


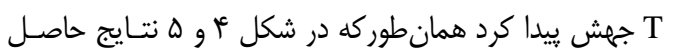

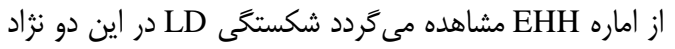

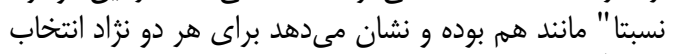
براى آلل T صورت كرفته است.

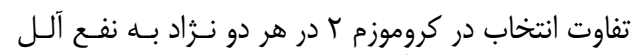

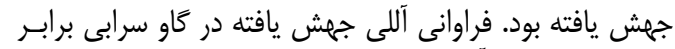

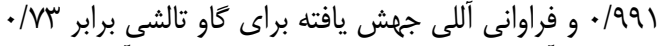

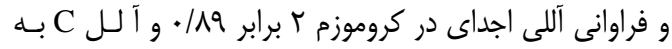
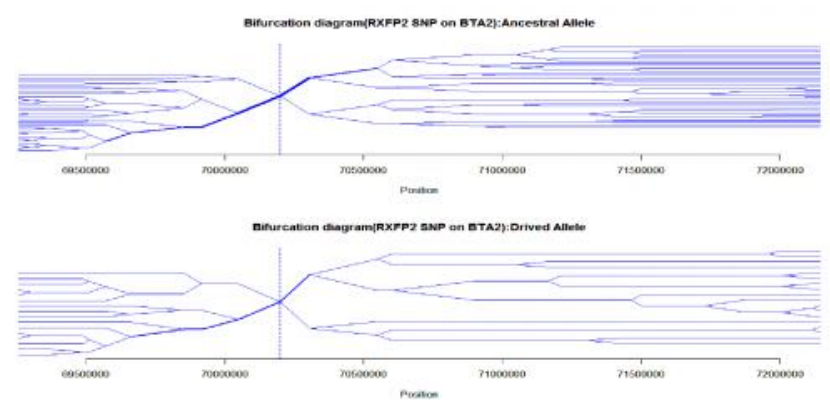

شكل ع- شكستخى LD براى الل اجدادى و جهش يافته در كروموزم ه براى نثزاد تالشى

Figure 6. LD brekage for ancestral and mutant allele on chromosome 5 for Taleshi breed
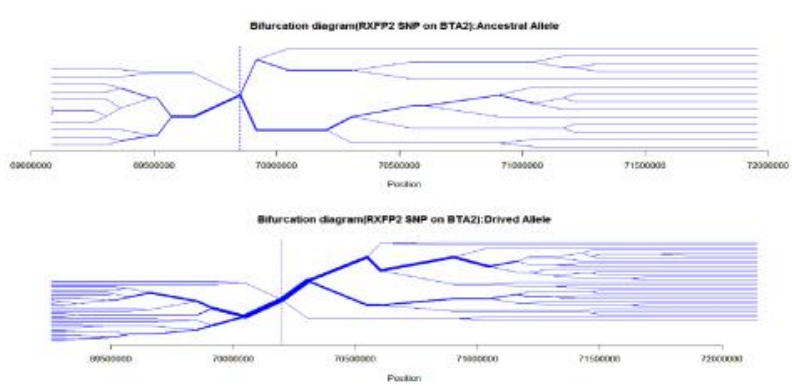

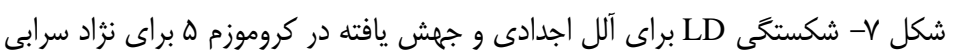

Figure 7. LD brekage for ancestral and mutant allele on chromosome 5 for Sarabi breed

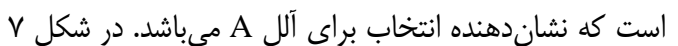

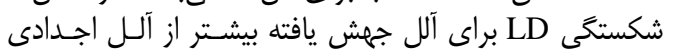

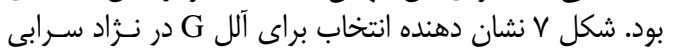

تفاوت انتخاب در كروموزم ه در نزاد تالشـى بــهـ نفـع آلـلـ

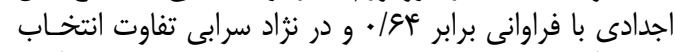

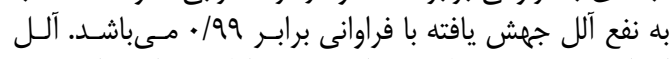

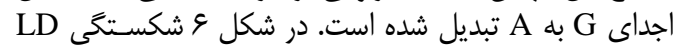

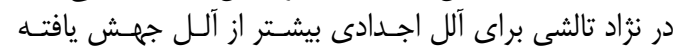
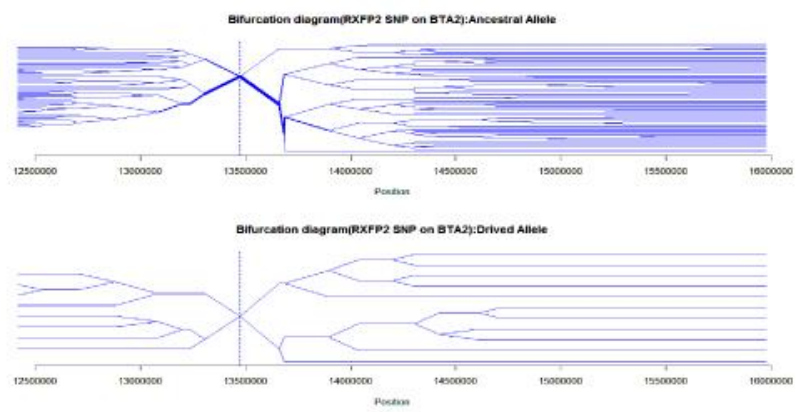

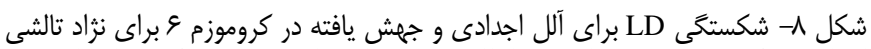

Figure 8. LD brekage for ancestral and mutant allele on chromosome 6 for Taleshi breed 

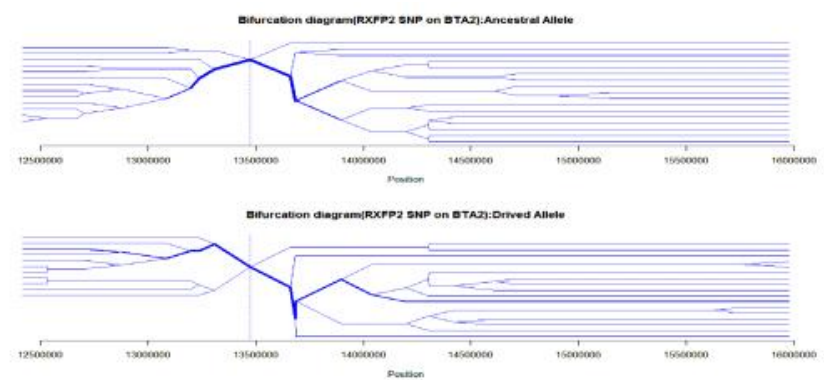

شكل q- شكستخى LD براى آلل اجدادى و جهش يافته در كروموزم \& براى نثراد سرابى

Figure 9. LD brekage for ancestral and mutant allele on chromosome 6 for Sarabi breed

است. شكستخى LD در شكل ^ و 9 نشاندهنده انتخاب بالا

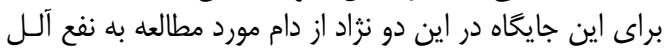

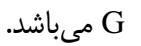

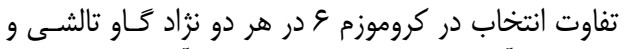

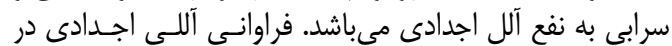

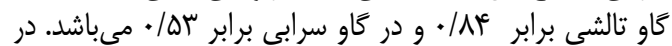

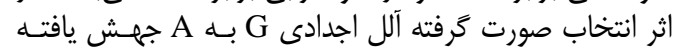

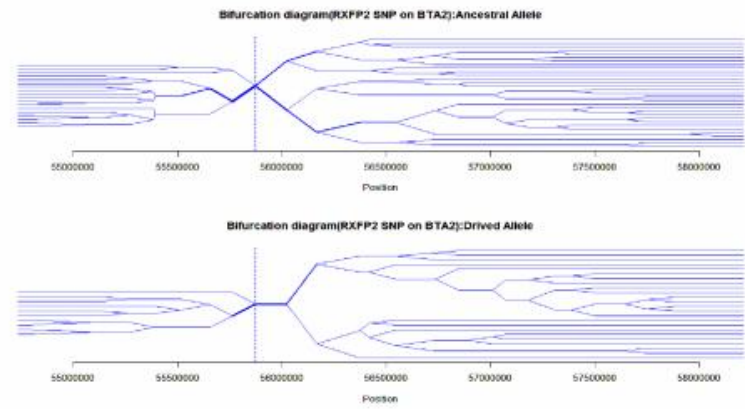

شكل • 1- شكستخى LD براى آلل اجدادى و جهش يافته در كروموزم V براى نثاد تالشى .LD

Figure 10. LD brekage for ancestral and mutant allele on chromosome 7 for Taleshi breed

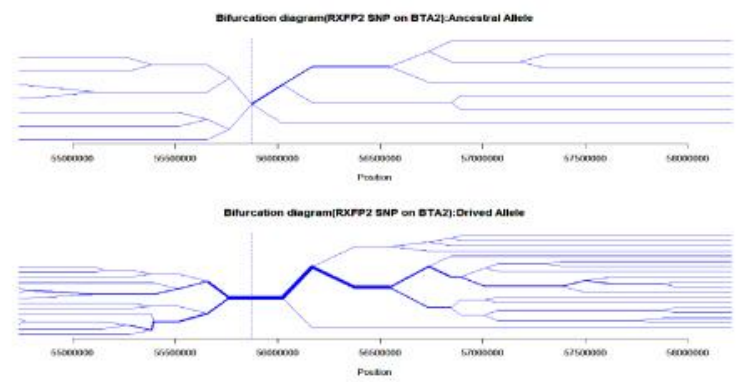

شكل II - شكستكى LD براى آلل اجدادى و جهش يافته در كروموزم V براى نزاد سرابى

Figure 11. LD brekage for ancestral and mutant allele on chromosome 7 for Sarabi breed

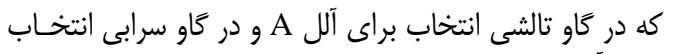

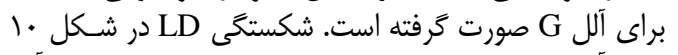

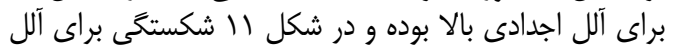
جهش يافته بالا مىباشد.

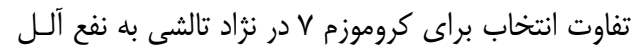

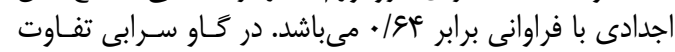

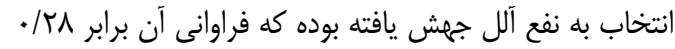

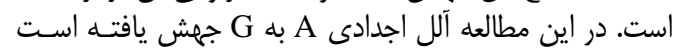



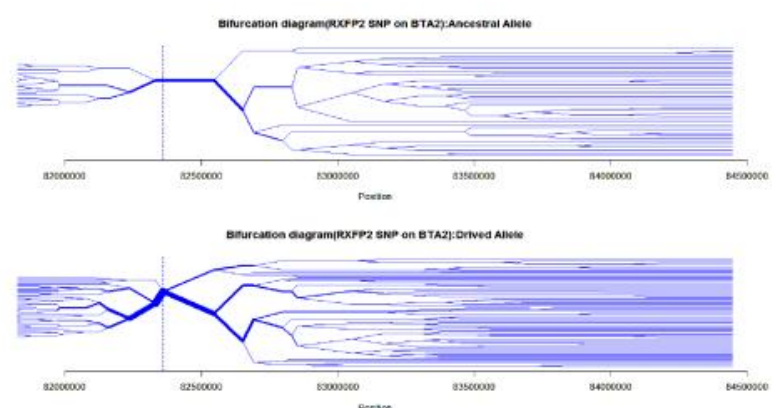

شكل r ا - شكستكى LD براى آلل اجدادى و جهش يافته در كروموزم • ا براى نثاد تالشى

Figure 12. LD brekage for ancestral and mutant allele on chromosome 10 for Taleshi breed
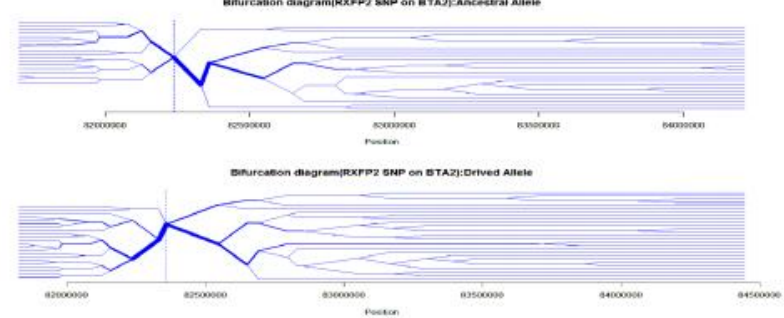

شكل سا - شكستكى LD براى آلل اجدادى و جهش يافته در كروموزم • ا براى نزاد سرابى

Figure 13. LD brekage for ancestral and mutant allele on chromosome 10 for Sarabi breed

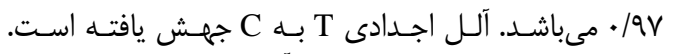

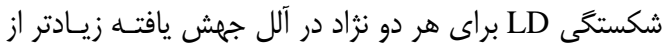

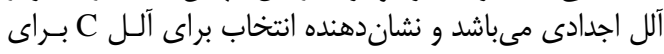
هر دو نزاد مىباشد.

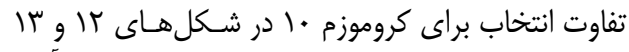

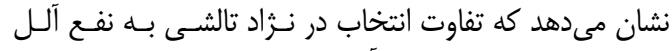

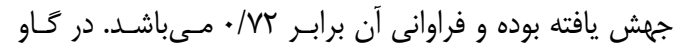

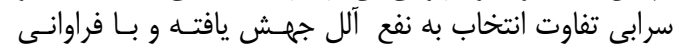
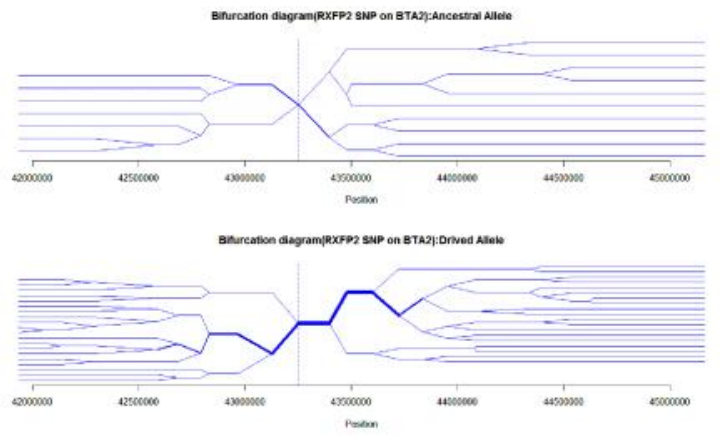

شكل عا( - شكستخى LD براى آلل اجدادى و جهش يافته در كروموزم r ب براى نزاد سرابى

Figure 14. LD brekage for ancestral and mutant allele on chromosome 22 for Sarabi breed 


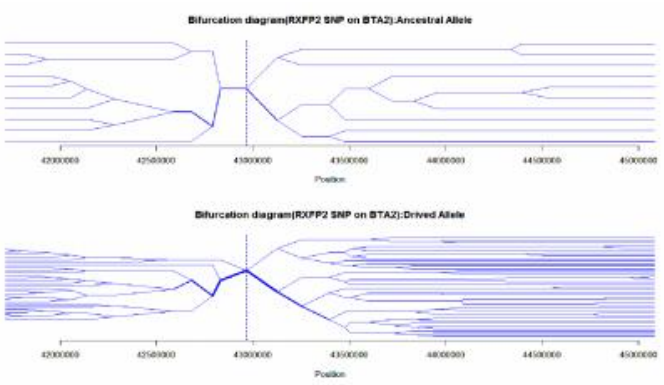

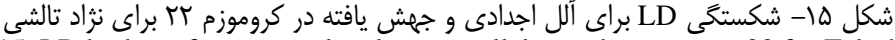

Figure 15. LD brekage for ancestral and mutant allele on chromosome 22 for Taleshi breed

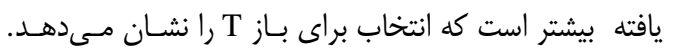

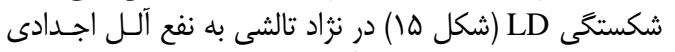

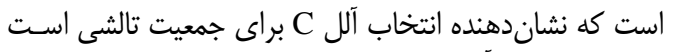

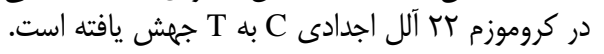

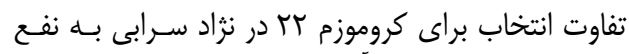

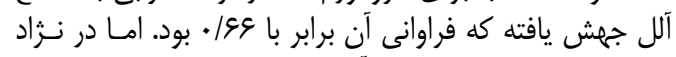

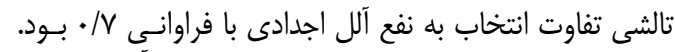

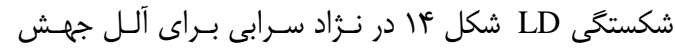

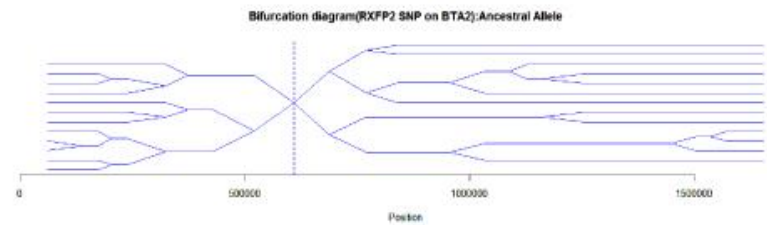

Pestect

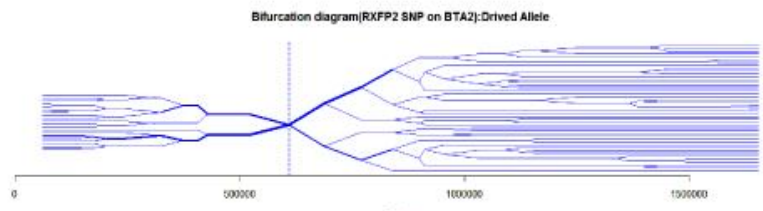

penter

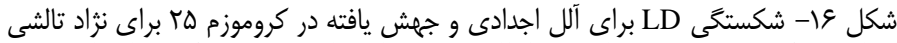

Figure 16. LD brekage for ancestral and mutant allele on chromosome 25 for Taleshi breed
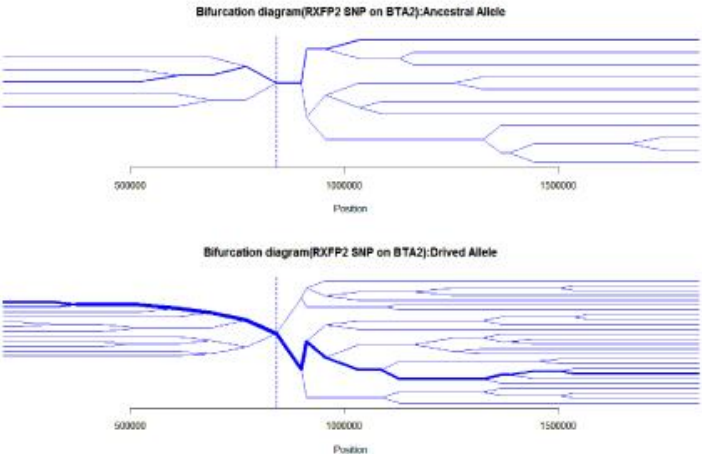

soccou

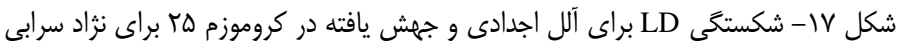

Figure 17. LD brekage for ancestral and mutant allele on chromosome 25 for Sarabi breed

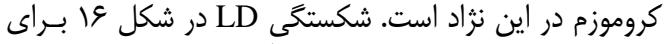

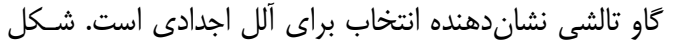

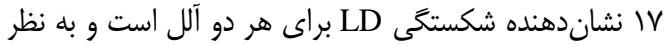

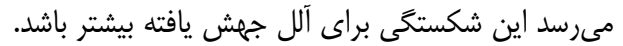

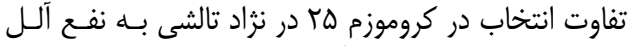

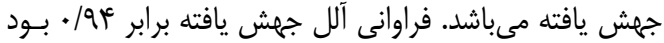

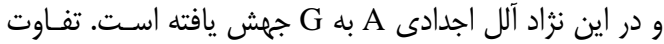

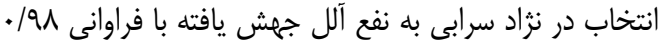

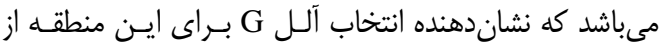




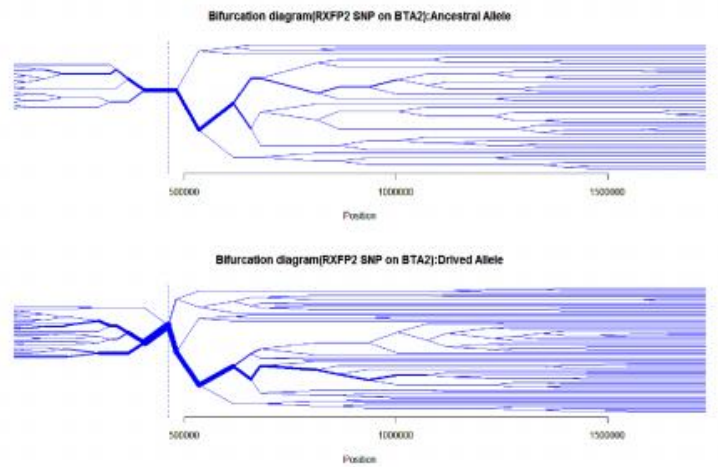

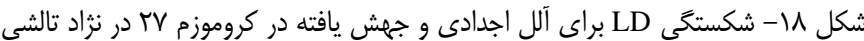

Figure 18. LD brekage for ancestral and mutant allele on chromosome 27 for Taleshi breed

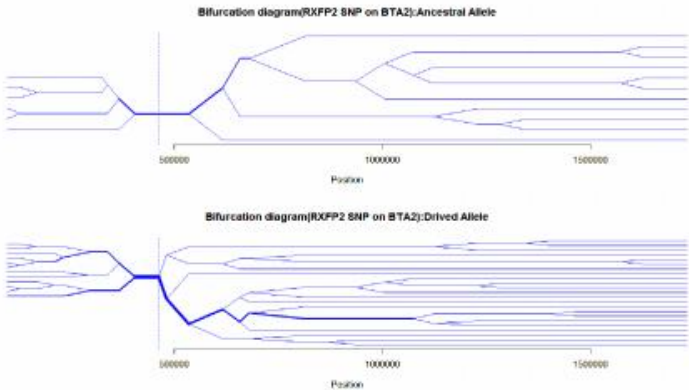

شكل 19 - شكستخى LD براى آلل اجدادى و جهش يافته در كروموزم TV دم نثاد سرابى

Figure 19. LD brekage for ancestral and mutant allele on chromosome 27 for Sarabi breed

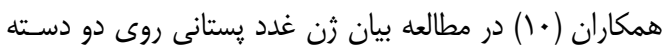

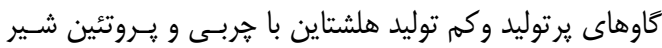

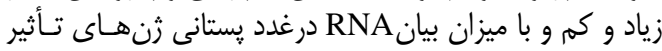
كذار از جمله

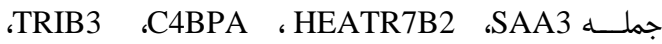
،BMX ،SLC25 A38 ،HSPD1 ،CHAC1 ، SESN2 ‘OKRT2 VEGFA ،CDH16 ،RPL23A ، ATF3 ،C3H14 PTHLH ،ARID1B ،CDKN1A ،EIF4G3 FCAMR DNER ،HIST1H2AC ،M-SAA32 ،DDT3

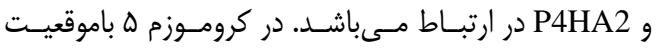
سF

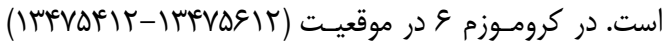
ثن بــا شــــاره شناســايى

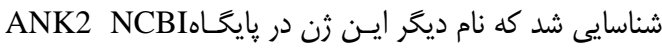

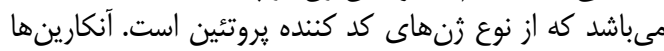

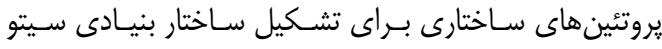

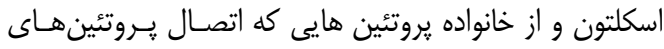

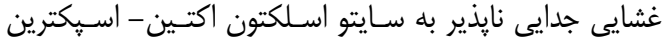

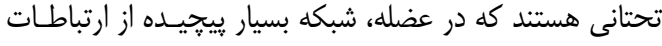

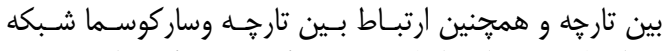

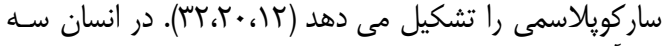
زن آنكيرين ANK

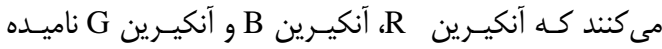

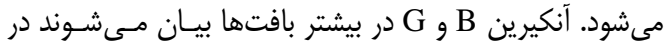

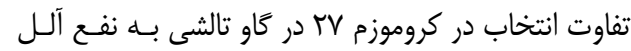

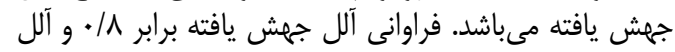

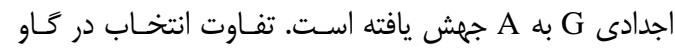

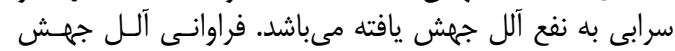

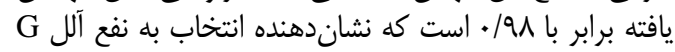

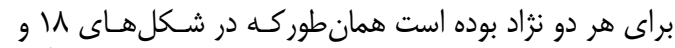

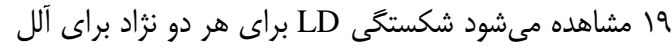

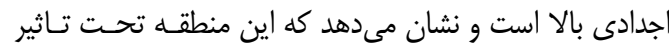

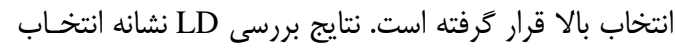

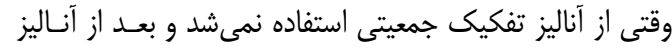

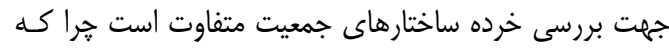

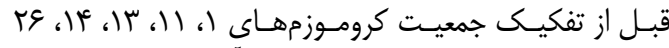

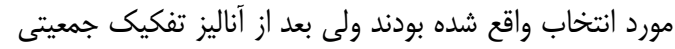

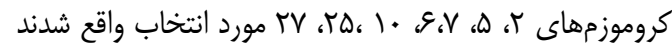

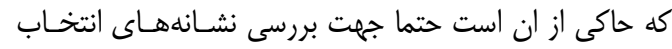

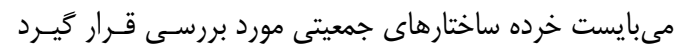

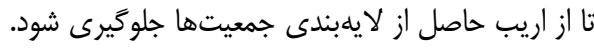

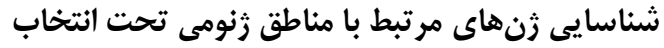

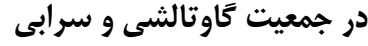

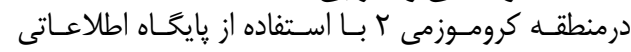

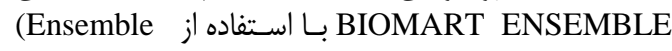

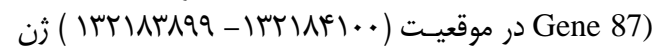
از RIF4G3 در انتقـال EIF4G

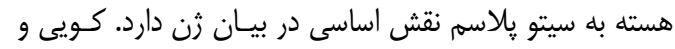




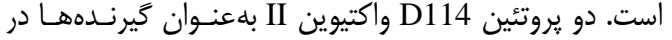

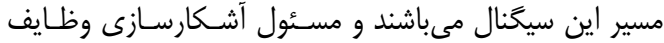

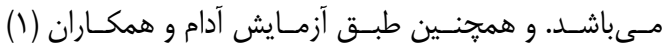

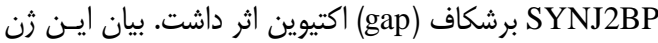

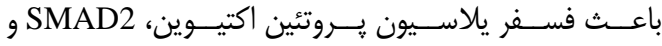

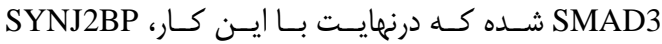

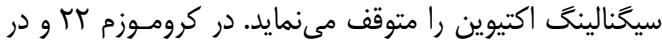

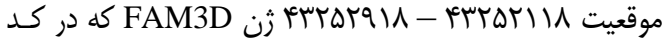

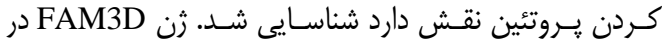

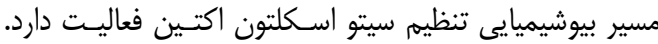
FAM3D،FAM3C ،FAM3B ،FAM3A خانواده شبه سيتوكين مىباشـند كـه FAM

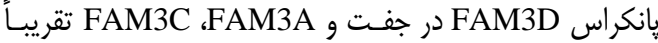

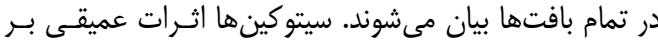

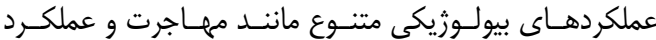

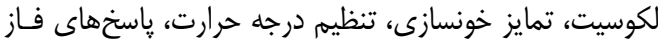
حاد و بقاى سلول دارند.

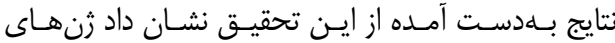

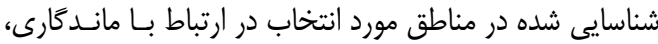

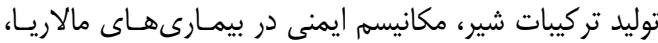

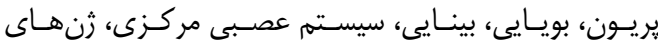

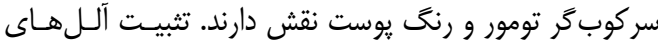

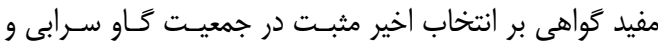

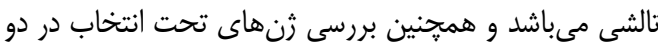

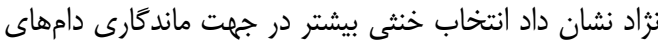
مورد مطالعه در محيط در حال رخ داد دادن مي بياشد.

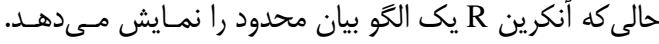

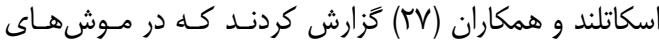

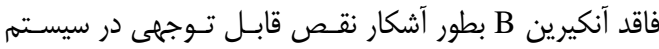

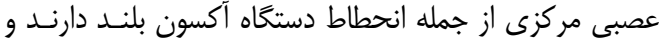

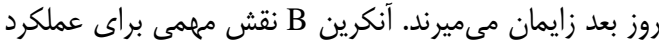

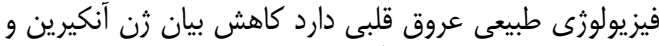

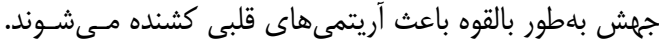

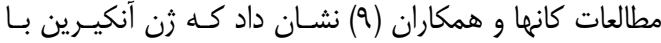

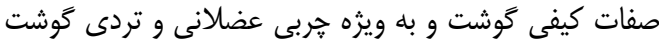

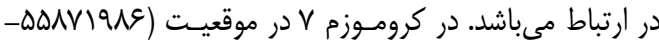

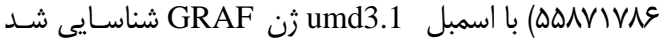
كه بdعنوان يك ثن كد كننده يروتئين كه نام يـروتئين آن

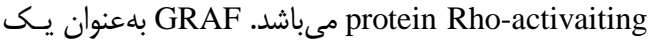

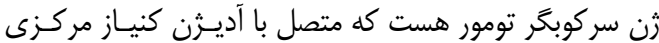

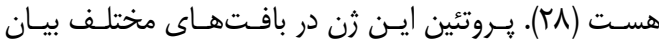

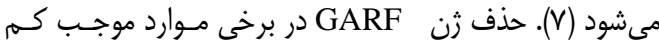

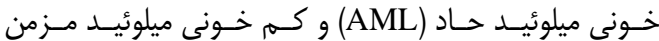

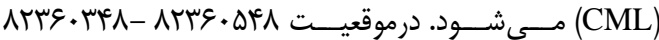

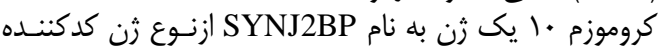

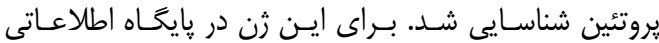
KeGG

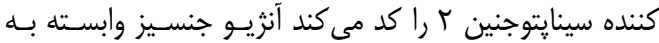

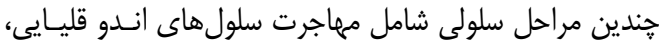

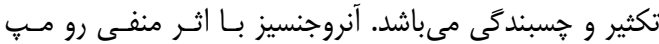

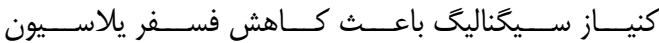

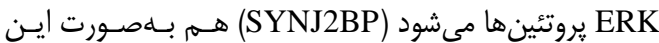

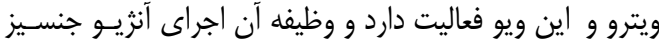

A. Feldner. W J. Yang. J. Wüstehube-Lausch. S.E. Herberich. M. Pind Stabilizes the Notch Ligands DLL1 and DLL4 and Inhibits Sprouting AngiogenesisNovelty and Significance. Circulation research, 113: 1206-1218.

2. Aminafshar, M., C. Amirinia and R. Vaez-Torshizi. 2008. Genetic diversity in buffalo population of Guilan using microsatellite markers. Journal Animal and Veterinary Advance, 7: 1499-1515.

3. Andersson, L. and M. Georges. 2004. Domestic-animal genomics: deciphering the genetics of complex traits. Nature Reviews Genetics, 5: 202-212.

4. Ardlie, K.G., L. Kruglyak and M. Seielstad. 2002. Patterns of linkage disequilibrium in the human genome. Nature Reviews Genetics. 3: 299-309.

5. Barrett. J.C.. B. Frv. J.D.M.J. Maller and M.J. Dalv. 2005. Haploview: analysis and visualization of LD and haplotype maps. Bioinformatics, 21: 263-265.

6. Browning, B. L. 2014. Homepage of software: BEAGLE v.4, URL http://faculty.washington.edu/browning/beagle/beagle.html.

7. Borkhardt, A., S. Bojesen, O.A. Haas, U. Fuchs, D. Bartelheimer, I.F. Loncarevic, R.M. Bohle, J. Harbott, R.U. ReppJaeger and S. Viehmann. 2000. The human GRAF gene is fused to MLL in a unique $\mathrm{t}(5 ; 11)(\mathrm{q} 31 ; \mathrm{q} 23)$ and both alleles are disrupted in three cases of myelodysplastic syndrome/acute myeloid leukemia with a deletion 5q.Proceedings of the National Academy of Sciences, 97: 9168-9173.

8. Brian, L. and B. Rowning. 2011. BEAGLE 3.3.2. Department of Medicine, Division of Medical Genetics, University of Washington.

9. Cunha, S.R., S. Le Scouarnec, J.J. Schott and P.J. Mohler. 2008. Exon organization and novel alternative splicing of the human ANK2 gene: implications for cardiac function and human cardiac disease. Journal of molecular and cellular cardiology, 45: 724-734.

10. Cui, X., Y. Hou, S. Yang, Y. Xie, S. Zhang, Y. Zhang, Q. Zhang, X. Lu, G.E. Liu and D. Sun. 2014 Transcriptional profiling of mammary gland in Holstein cows with extremely different milk protein and fat percentage using RNA sequencing. BMC genomics, 15: 1 
11. Fan, B., Z. Du, D.M. Gorbach and F. RM. 2010. Development and Application of High-density SNP Arrays in Genomic Studies of Domestic Animals. Asian-Australia journal Animal Science, 2: 833847.

12. Gagelin, C., B. Constantin, C. Deprette, M.A. Ludosky, M. Recouvreur, J. Cartaud, C. Cognard, G. Raymond and E. Kordeli. 2002. Identification of AnkG107, a muscle-specific ankyrin-G isoform. Journal of Biological Chemistry, 277: 12978-12987.

13. Giacomoni, E.H., G.P. Fernandez-Stolz and T.R.O. Freitas. 2008. Genetic diversity in the Pantaneiro horse breed assessed using microsatellite DNA markers. Genetic. Molecular. Research, 7: 261-270.

14. Gautier, M. and R. Vitalis. 2012. Rehh: An R package to detect footprints of selection in genomewide SNP data from haplotype structure. Bioinformatics, 28: 1176-1177.

15. Gross, A., A. Tönjes, P. Kovacs, Peter Kovacs, Krishna R Veeramah, Peter Ahnert, Nab R Roshyara, Christian Gieger, Ina-Maria Rueckert, John Novembre, Michael Stumvoll, Markus Scholz. 2011. Population-genetic comparisons of the Sorbian isolate population in Germany with the German KORA population using genome-wide SNP arrays. BMC Genetics, 12: 67.72.

16. Holsinger, K.E. and B.S. Weir. 2009. Genetics in geographically structured populations: defining, estimating and interpreting FST. Nature reviews. Genetics, 10: 639-650.

17. Kijas, J.W., J.A. Lenstra, B. Hayes, Simon Boitard, Laercio R. Porto Neto,Magali San Cristobal, Bertrand Servin, Russell McCulloch, Vicki Whan, Kimberly Gietzen, Samuel Paiva, William Barendse, Elena Ciani, Herman Raadsma, John McEwan, Brian Dalrymple, other members of the International Sheep Genomics Consortium. 2012. Genome-Wide Analysis of the World's Sheep Breeds Reveals High Levels of Historic Mixture and Strong Recent Selection. PLoS Biologics, 10: $12-58$.

18. McKav. S.D.. R.D. Schnabel. B.M. Murdoch. L.K. Matukumalli. J. Aerts. W. Coppieters. D. Crews. E.D. Neto. C.A. Gill. C. Gao and H. Mannen. 2008. An assessment of population structure in eight breeds of cattle using a whole genome SNP panel. Bmc Genetics, 9: 37-42.

19. Mokhber, M., M. Moradi Shahrebabak, M. Sadeghi, H. Moradi Shahrebabak and G. Williams. 2015. Genomics explore of selection signature in buffalo signs of Khuzestan and Mazandaran. Journal of Iran Animal Science, 46: 119-131 (In Persian).

20. Nelson, W.J. and E. Lazarides. 1984. Goblin (ankyrin) in striated muscle: identification of the potential membrane receptor for erythroid spectrin in muscle cells. Proceedings of the National Academy of Sciences, 81: 3292-3296.

21. Nei, M. 1973. Analysis of Gene Diversity in Subdivided Populations, Proc. Nature. Academic. Science, 70: 3321-3323.

22. Pan, D., S. Zhang, J. Jiang, L. Jiang, Q. Zhang and J. Liu. 2013. Genome-wide detection of selective signature in Chinese Holstein. PLoS ONE. ;8:e60440. doi: 10.1371/journal.pone, 40-44.

23. Porter, N.C., W.G. Resneck, A. O'Neill, D.B.Van Rossum, M.R. Stone and R.J. Bloch. 2005. Association of small ankyrin 1 with the sarcoplasmic reticulum. Molecular membrane biology, 22: 421-432.

24. Pritchard, J.K. and M. Przeworski. 2001. Linkage disequilibrium in humans: models and data. American Journal of Human genetics, 69: 1-14.

25. Purcell, S., B. Neale, K. Todd-Brown, L. Thomas, M.A.R. Ferreira, D. Bender, J. Maller, P. Sklar, P.I.W. de Bakker, M.J. Daly and P.C. Sham. 2007 PLINK: a toolset for whole-genome association and population-based linkage analysis. American Journal of Human Genetics, 81: 559-575.

26. Price, A.L., N.J. Patterson, R.M. Plenge, M.E. Weinblatt, N.A. Shadick and D. Reich. 2006. Principal components analysis corrects for strati cation in genome-wide association studies. Nature Genetics, 38: 904-909.

27. Qanbari, S., J. Pimentel ECG, G. Tetens, P. Thaller Lichtner and AR. Sharifi. 2010. A genome-wide scan for signatures of recent selection in Holstein cattle. Animal Genetics, 41: 377-89.

28. Qian, Z., J. Qian, J. Lin, D.M. Yao, Q. Chen, R.B. Ji, Y. Li, G.F. Xiao and J.Y. Li. 2010. GTPase regulator associated with the focal adhesion kinase (GRAF) transcript was down-regulated in patients with myeloid malignancies. Journal of Experimental \& Clinical Cancer Research, 29: 1pp.

29. Sabeti, P.C., D.E. Reich, J.M. Higgins, H.Z.P. Levine, D.J. Richter, S.F. Schaffner, S.B. Gabriel, J.V. Platko, N.J. Patterson and G.J. McDonald. 2002. Detecting recent positive selection in the human genome from Hanlotvne structure. Nature. 419: 832-837.

30. Scheet. P. and M. Stephens. 2006. A fast and flexible statistical model for large-scale population genotvpe data: applications to inferring missing genotypes and haplotypic phase. The American Journal of Human Genetics, 78: 629-644.

31. Scotland, P., D. Zhou, H. Benveniste and V. Bennett.1998. Nervous system defects of AnkyrinB (-/-) mice suggest functional overlap between the cell adhesion molecule L1 and 440-kD AnkyrinB in premyelinated axons. The Journal of cell biology, 143: 1305-1315.

32. Tuvia, S., M. Buhusi, L. Davis, M. Reedy and V. Bennett. 1999. Ankyrin-B is required for intracellular sorting of structurally diverse $\mathrm{Ca} 2+$ homeostasis proteins. The Journal of cell biology, 147: 995-1008.

33. Weir. B.S. and C.C. Cockerham. 1984. Estimating F-statistics for the analysis of population structure. International Journal of Evolutionary Biology, 38: 1358-1370. 


\title{
Genome-Wide Scan for Selection Signatures in Iranian Sarabi and Taleshi Indigenous Breed
}

\author{
Seyed Makan Mosavi Kashani ${ }^{1}$, Ghodrat Rahimi Mianji ${ }^{2}$ and \\ Hossein Moradi Shahrbabak ${ }^{3}$ \\ 1 and 2- Ph.D. Student Professor, Department of Animal Science, Sari Agricultural Science and Natural Resources \\ University \\ 3- Assistant Professor, Department of Animal Science, University of Tehran \\ (Corresponding author: hmoradis@ut.as.ir) \\ Received: January 17, $2017 \quad$ Accepted: May 7, 2017
}

\begin{abstract}
The aim of this study was to find the footprint of selection in native Sarabi and Taleshi cattle breeds 296 cattle from two breeds were sampled and genotyped. by $40 \mathrm{k}$ microarray of illumine company. 43 animals were removed because their ACR was below 0.09. Markers were filtered with minor allele frequency (MAF) equal 0.01 and Hardy-Weinberg equilibrium test $\left(10^{-6}\right)$. After filtering, 28782 markers remained. To study the genetic structure of population and subpopulation principal component analysis (PCA) was used. To identify selective signals for Sarabi and Taleshi pure population theta parameter was calculated. To reduce error theta values was averaged with near marker and Manhattans graph were obtained by haploview software. Chromosomes 2, 5, 6, 7, 10, 22, 25 and 27 had selection signatures. To searching for selection signatures in both population, extended haplotype homozygosity statistics (EHH) was calculated using $\mathrm{R}$ software. In addition, for each chromosome LD erosion rate for ancestral and mutant alleles were calculated. To study of positions that showed signature selection, bioinformatics web site were searched. EIF4G3 gene was identified on chromosome 2. This gene have fundamental role in transfering RNA from nucleus to the cytoplasm and gene expression. ANK2 gene was identified on chromosome 6 which encodes polypeptide ankirin B expressed in all tissues. On chromosome 7 the gene ARHGAP26 was found which is a tumor suppressor genes. On chromosome 10, a gene identified that encodes protein SYNJ2BP that suppress activing protein. On chromosome 22, FAM3D protein coding gene detected that plays a role in cyto sckeleton actin biochemical pathway. This gene is expressed in the placenta and plays a role in biological functions such as migration and function of leukocyte, temperature regulation, cell survival and hematopoiesis differentiation.
\end{abstract}

Keywords: Extended Haplotype Homozygosity, Principal Component Analysis, Selection Signature, Statistics Theta 